\title{
Estimating Probable Maximum Precipitation by Considering Combined Effect of Typhoon and Southwesterly Air Flow
}

\author{
Cheng-Chin Liu ${ }^{1}$, Tao-Chang Yang ${ }^{1}$, Chen-Min Kuo ${ }^{1}$, Jau-Ming Chen ${ }^{2}$, and Pao-Shan Yu ${ }^{1, *}$ \\ ${ }^{1}$ Department of Hydraulic and Ocean Engineering, National Cheng-Kung University, Tainan City, Taiwan, R.O.C. \\ ${ }^{2}$ Institute of Maritime Information and Technology, National Kaohsiung Marine University, Kaohsiung City, Taiwan, R.O.C.
}

Received 25 October 2015, revised 27 March 2016, accepted 28 March 2016

\begin{abstract}
Typhoon Morakot hit southern Taiwan in 2009, bringing 48-hr of heavy rainfall [close to the Probable Maximum Precipitation (PMP)] to the Tsengwen Reservoir catchment. This extreme rainfall event resulted from the combined (co-movement) effect of two climate systems (i.e., typhoon and southwesterly air flow). Based on the traditional PMP estimation method (i.e., the storm transposition method, STM), two PMP estimation approaches, i.e., Amplification Index (AI) and Independent System (IS) approaches, which consider the combined effect are proposed in this work. The AI approach assumes that the southwesterly air flow precipitation in a typhoon event could reach its maximum value. The IS approach assumes that the typhoon and southwesterly air flow are independent weather systems. Based on these assumptions, calculation procedures for the two approaches were constructed for a case study on the Tsengwen Reservoir catchment. The results show that the PMP estimates for 6- to 60-hr durations using the two approaches are approximately 30\% larger than the PMP estimates using the traditional STM without considering the combined effect. This work is a pioneer PMP estimation method that considers the combined effect of a typhoon and southwesterly air flow. Further studies on this issue are essential and encouraged.
\end{abstract}

Key words: Probable Maximum Precipitation, Southwesterly air flow, Typhoon, Combined effect, Storm transposition method

Citation: Liu, C. C., T. C. Yang, C. M. Kuo, J. M. Chen, and P. S. Yu, 2016: Estimating Probable Maximum Precipitation by considering combined effect of typhoon and southwesterly air flow. Terr. Atmos. Ocean. Sci., 27, 991-1003, doi: 10.3319/TAO.2016.03.28.01(Hy)

\section{INTRODUCTION}

Probable Maximum Precipitation (PMP) is an important rainfall-runoff model input for estimating Probable Maximum Flood (PMF) which is the key design criterion for reservoir hydraulic features. The World Meteorological Organization (WMO) defines PMP as the greatest depth of precipitation for a given duration meteorologically possible for a given size storm area at a particular location at a particular time of the year, with no allowance made for longterm climatic trends (WMO 1986).

Typhoon Morakot caused great damage to Taiwan in 2009 (Li et al. 2014). Besides the inestimable loss of facilities and properties, 675 people died, 54 people were injured or missing, 1626 houses collapsed and the product losses amounted to 6.07 billion US dollars (Hsieh et al. 2010). From the lessons learned from Typhoon Morakot, flood prevention strategies have been adjusted (Hsieh et al. 2010)

\footnotetext{
* Corresponding author

E-mail:yups@mail.ncku.edu.tw
}

and flood warning improvements proposed (Yu et al. 2014a, b). Many studies have investigated and discussed why Typhoon Morakot brought such extreme rainfall (Chien and Kuo 2011; Van Nguyean and Chen 2011; Fang et al. 2011; Lee et al. 2011; Tao et al. 2011; Wu et al. 2011; Yen et al. 2011). These studies concluded that the combined effect of the typhoon and southwesterly air flow, and the orographic effect in southwestern Taiwan were the two key factors causing such extreme rainfall. The combined effect of the typhoon and southwesterly air flow enhanced the moisture supplement from the southwesterly air flow to the typhoon. The orographic effect means that the local rainfall is strongly affected by the island mountains when typhoons pass over the island of Taiwan and its vicinity (Lin et al. 2011). The topography of Taiwan is shown in Fig. 1 with more than two hundred peaks over $3000 \mathrm{~m}$ in height. Heavy rainfall resulting from the orographic effect on the typhoon circulation is truly a serious threat to Taiwan (Fang et al. 2011). During Typhoon Morakot, the tremendous rainfall 
concentrated in the mountain areas of Chaiyi County and Kaohsiung City, located in southern Taiwan where fifteen rainfall stations gauged maximum 72-hr rainfalls larger than $2000 \mathrm{~mm}$. Among these stations, Alishan meteorological station had a total rainfall of $2884 \mathrm{~mm}$ and a 48-hr rainfall of $2361 \mathrm{~mm}$ which broke the highest record in Taiwan. Rainfall of longer duration greater than $24 \mathrm{hr}$ are close to the world records, as shown in Fig. 2. During Typhoon Morakot, the observed 24-hr rainfall in the Renyitan Reservoir catchment $(1191 \mathrm{~mm})$ was greater than the 24-hr PMP for the Renyitan Reservoir (1086 mm) and the observed 24-hr rainfall in the Nanhua Reservoir catchment (1201 mm) approaching the 24-hr PMP of Nanhua Reservoir (1474 mm). Therefore, the PMP estimation for each reservoir should be reevaluated by considering the combined effect of typhoon and southwesterly air flow (under the similar scenario to Typhoon Morakot) to ensure the safety of each reservoir after Typhoon Morakot, especially for the most important reservoir in Taiwan.

Many methods have been proposed for PMP estimation.

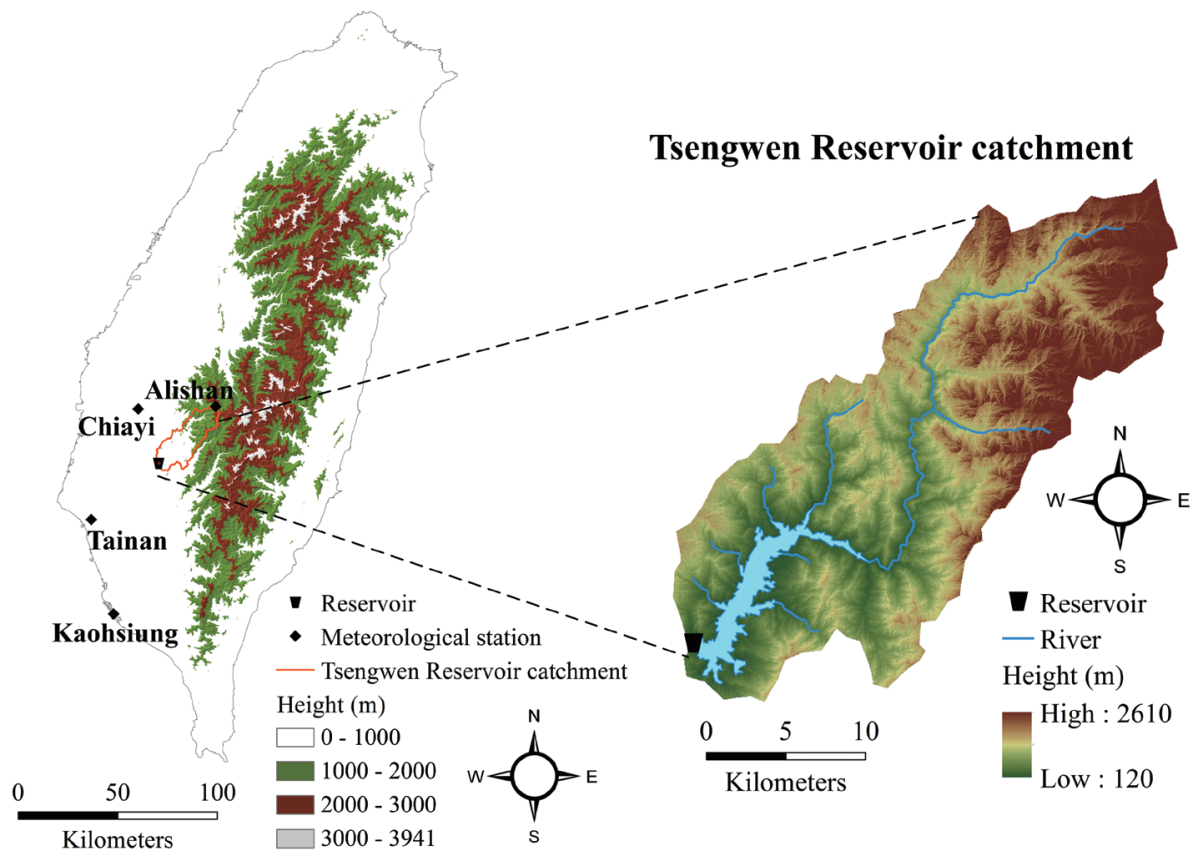

Fig. 1. Study area and locations of meteorological stations. (Color online only)

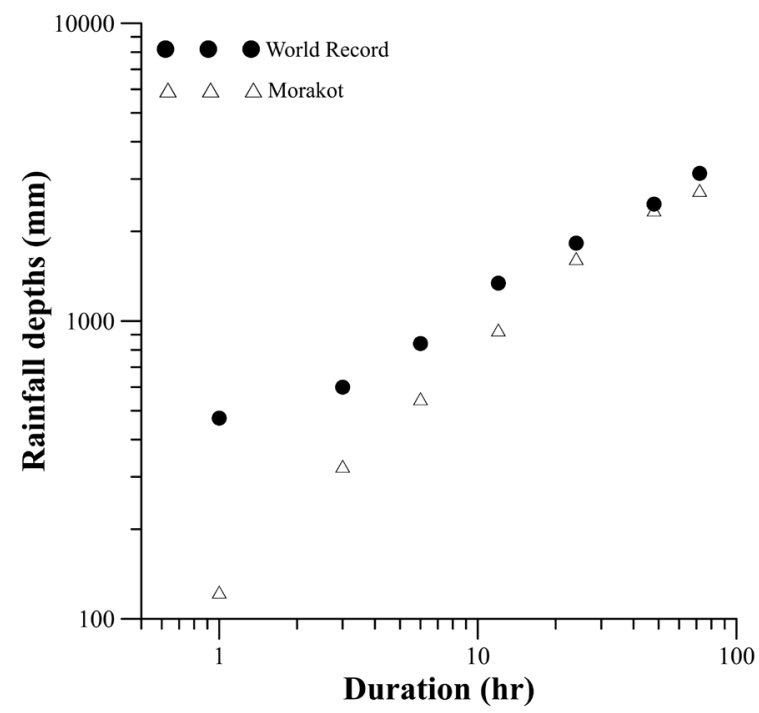

Fig. 2. Rainfall depths of world record and Typhoon Morakot (2009). The world record data were obtained from the ANNEX II of Manual on Estimation of Probable Maximum Precipitation (PMP) (WMO 2009). 
The concept of each method can be categorized simply as either statistical methods or hydrometeorological methods (Rakhecha and Kennedy 1985; Abbs 1999; Douglas and Barros 2003; Chen and Bradley 2007; Fernando and Wickramasuriya 2011; Casas et al. 2011). PMP estimation method using numerical weather models have also been developed in recent years (Tan 2010; Yigzaw et al. 2013; Ishida et al. 2015). For the multifarious methods, the hydrometeorological methods is a practical one and worldwide used for PMP estimation (Kulkarni et al. 2010). It is time to embrace a hydrometeorological approach as the guideline for dam design and operations for the $21^{\text {st }}$ century (Hossain et al. 2010). The storm transposition method (STM) is one of the hydrometeorological methods used to calculate PMP estimation in Taiwan. In STM, an extraordinarily large storm in the adjacent area is transposed to the design area or a specific location. This is accomplished in four major steps: selecting a control storm, transposing it to the project site, maximizing it and enveloping it. The control storm is selected from the most severe, historic, tropical storms (Fan 1992). This approach increases the sample size of historical storms that could be used for PMP estimation (Micovic et al. 2015). Details of STM can be found in the manual of WMO (2009). STM is adopted in this work to construct the PMP estimation method considering the combined effect of typhoon and southwesterly air flow due to STM is the conventional meteorological method for PMP estimation in Taiwan and the combined effect of typhoon and southwesterly air flow is not considered in the procedure of STM.

For the aforementioned reasons: (1) the combined effect of typhoon and southwesterly air flow, and the terrain effect are the key factors leading to tremendous rainfall in Taiwan; (2) the observed 24-hr rainfalls are found to exceed or approach the PMP estimates using the traditional STM in some reservoir catchments during Typhoon Morakot; and (3) the traditional STM does not consider the combined effect of typhoon and southwesterly air flow, it is important to consider the combined effect in the PMP estimation procedure, which greatly motivates this work to propose new PMP estimation approaches with consideration of the combined effect.

Based on STM, this study proposes two approaches [i.e., the amplification index (AI) approach and the independent system (IS) approach] for considering the combined effect of typhoon and southwesterly air flow in PMP estimation. For the rest part of this paper, it is divided into four sections. Section 2, Study Area and Data Set, describes the study area and data set used in the study. Section 3, Methodology, states the hypotheses and calculation procedures of the AI and IS approaches. Section 4, Results and Discussions, gives the PMP estimation results using the AI and IS approaches, compared with the PMP estimates from the traditional STM without considering the combined effect of typhoon and southwesterly air flow, and discusses the rationality of the proposed approaches. Finally, the conclusions and future works section concludes this paper and presents our future work.

\section{STUDY AREA AND DATA SET}

The study area is the Tsengwen Reservoir catchment (Fig. 1). Tsengwen Reservoir is the biggest reservoir in southern Taiwan, with a storage capacity of 708 million $\mathrm{m}^{3}$. It is located upstream of Tsengwen Creek and has been operating since 1973 for multiple functions including irrigation, hydraulic power generation, water supply and flood prevention. The catchment area is around $480 \mathrm{~km}^{2}$ with an average elevation of approximately $963 \mathrm{~m}$. The mean annual rainfall in the catchment is about $3000 \mathrm{~mm}$. Most of the rainfall is concentrated during the wet season (from May to October).

In order to determine the representative stations for PMP estimation using the STM, the hourly dew point data at Chiayi (1969 - 2010), Tainan (1951 - 2010), Kaohsiung (1951 - 2010), and Alishan (1951 - 2010) meteorological stations (Fig. 1) were collected. The southwesterly air flow precipitation (SFP) events were selected based on the rainfall and wind-direction angle records at Alishan meteorological station from May to August from 1979 - 2010. The SFP event selection standards are as follows: (1) the rainfall spell length is equal to or longer than 5 days to avoid selecting rainfall events caused by thunder storms; (2) the 1-day and 2-day rainfalls are greater than 200 and $300 \mathrm{~mm}$, respectively; and (3) the southwest wind blows during the rainfall event. The $200 \mathrm{~mm}$ threshold for 1-day rainfall is defined by the Water Resources Agency of Taiwan as the warning threshold for probable flooding. The $300 \mathrm{~mm}$ threshold for 2-day rainfall is defined by the Soil \& Water Conservation Bureau of Taiwan as the warning threshold for probable debris flow or landslide. Based on the former selection standards, 14 SFP events were selected as listed in Table 1. For each SFP event selected using the former standards, it was found that approximately $90 \%$ of the rainfall was concentrated in the first two days. Therefore, the persistence of a SFP event is defined as 2 days. The rainfalls for the first and second days for each SFP event are listed in Table 1.

Cheung et al. (2008) indicated that a typhoon induces warm and moist southwesterly air flow during the summer monsoon season, which usually occurs when the typhoon center is in northern Taiwan. Based on the typhoon route classification map provided by the Central Weather Bureau (CWB) of Taiwan (Fig. 3), historical typhoons with routes $1,2,3$, and 6 are more likely to induce southwesterly air flow. Based on the four routes, 20 typhoon events, listed in Table 2, were selected for the study case.

Chien (2015) indicated that moisture transposition is a key factor that influences rainfall amount during the southwesterly air flow period which transports the moisture from the ocean southwest of Taiwan toward Taiwan. The moisture transposition is dominated mainly by two variables 
(i.e., wind velocity and precipitable water). Therefore, to establish the regression equation for SFP estimation, three kinds of daily data from 1979 - 2010 were collected in this study. This data includes (1) observed rainfall, (2) 10-m wind velocity, and (3) precipitable water. Data from May to August were utilized because the southwest monsoon occurs during this period in Taiwan. Observed rainfalls were collected at Alishan meteorological station. The data from $10-\mathrm{m}$ wind velocity (grid resolution: $0.32^{\circ} \times 0.32^{\circ}$; domain: $\mathrm{E} 110^{\circ}-\mathrm{E} 130^{\circ}, \mathrm{N} 15^{\circ}-\mathrm{N} 30^{\circ}$ ) and precipitable water (grid resolution: $0.5^{\circ} \times 0.5^{\circ}$; domain: $\mathrm{E} 110^{\circ}-\mathrm{E} 130^{\circ}, \mathrm{N} 15^{\circ}-$ $\mathrm{N} 30^{\circ}$ ) were collected from the Climate Forecast System Reanalysis (CFSR) data provided by the National Centers for Environmental Prediction (NCEP) (Saha et al. 2010) were designed and executed as a global, high resolution, coupled atmosphere-ocean-land surface-sea ice system to provide the best estimate for the state of these coupled domains over the period 1979 to present. Details on NCEP CFSR data can be found in the literature of Saha et al. (2010). The NCEP CFSR data were used in many studies with good climate/ oceanic system simulations (Wang et al. 2011; Xue et al. 2011; Bao and Zhang 2013; Chawla et al. 2013).

\section{METHODOLOGY}

In order to consider the combined effect of typhoon and southwesterly air flow on PMP estimation, two approaches (i.e., AI and IS approaches) are proposed considering the orographic effect based on the STM. The orographic effect is an important factor that leads to heavy rainfall. The STM estimation procedure includes elevation and barrier adjustments. The elevation adjustment involves that if the storm elevation is not at mean sea level but occurs at some elevated place, a correction is to be applied for the storm elevation. Barrier adjustment is required when there is a barrier or mountain range in the path of moisture being fed into the storm area. The details involving these two adjustments for the orographic effect can be found in the literatures of WMO (2009), Rakhecha and Singh (2009), and Lagos-Zúñiga and Vargas M. (2014). The traditional PMP estimation using STM is as follows:

$P M P_{n}=\frac{\omega_{\max }}{\omega} \times P_{n}=M M F \times P_{n}$

where $P M P_{n}$ means the PMP estimation for $n$-hr duration, which envelops the PMP estimations of all selected typhoon events; $\omega$ indicates the precipitable water in a specific storm; $\omega_{\max }$ denotes the maximum precipitable water in the study area; $P_{n}$ is the $n$-hr rainfall depth calculated by the Depth-Area-Duration (DAD) curves for a specific storm; $M M F$ represents the moisture maximization factor.

Table 1. Information on 14 SFP events including rainfalls at Alishan meteorological station, uv in CR, and prw in CR.

\begin{tabular}{|c|c|c|c|c|c|c|c|}
\hline \multirow{2}{*}{ SFP No. } & \multirow{2}{*}{ Date } & \multirow{2}{*}{ Year } & \multicolumn{3}{|c|}{ Rainfall (mm day $\left.{ }^{-1}\right)$} & \multirow{2}{*}{$\begin{array}{c}\mathbf{u v}^{\mathrm{a}} \\
\left(\mathrm{m} \mathrm{s}^{-1} \mathbf{d a y}^{-1}\right)\end{array}$} & \multirow{2}{*}{$\begin{array}{c}\mathbf{p r w}^{\mathbf{b}} \\
\left(\mathbf{m m} \mathbf{d a y}^{-1}\right)\end{array}$} \\
\hline & & & $1^{\text {st }}$ day & $2^{\text {nd }}$ day & Average & & \\
\hline 1 & $5 / 28-5 / 29$ & 1984 & 203.3 & 125.4 & 164.4 & 5.8 & 59.1 \\
\hline 2 & $5 / 28-5 / 29$ & 1985 & 282.6 & 78.4 & 180.5 & 8.3 & 62.1 \\
\hline 3 & $5 / 22-5 / 23$ & 1988 & 223.4 & 153.2 & 188.3 & 6.0 & 59.9 \\
\hline 4 & $5 / 23-5 / 24$ & 2010 & 305.0 & 3.5 & 154.3 & 7.2 & 54.1 \\
\hline 5 & $6 / 2-6 / 3$ & 1983 & 121.4 & 382.7 & 252.1 & 9.0 & 57.1 \\
\hline 6 & $6 / 23-6 / 24$ & 1991 & 296.5 & 387.0 & 341.8 & 9.4 & 63.0 \\
\hline 7 & $6 / 7-6 / 8$ & 1998 & 160.5 & 254.0 & 207.3 & 7.5 & 60.1 \\
\hline 8 & $6 / 7-6 / 8$ & 2003 & 287.5 & 50.0 & 168.8 & 7.1 & 63.2 \\
\hline 9 & $6 / 9-6 / 10$ & 2006 & 811.5 & 348.5 & 580.0 & 9.5 & 63.2 \\
\hline 10 & $7 / 23-7 / 24$ & 1981 & 493.7 & 28.5 & 261.1 & 9.4 & 62.3 \\
\hline 11 & $7 / 27-7 / 28$ & 2010 & 156.4 & 386.9 & 271.7 & 8.4 & 63.4 \\
\hline 12 & $7 / 26-7 / 27$ & 1989 & 240.5 & 189.0 & 214.8 & 8.5 & 62.2 \\
\hline 13 & $8 / 13-8 / 14$ & 1988 & 127.4 & 536.0 & 331.7 & 8.6 & 64.7 \\
\hline 14 & $8 / 12-8 / 13$ & 2007 & 155.0 & 227.0 & 191.0 & 7.8 & 66.5 \\
\hline
\end{tabular}

Note: $a$ : uv is the average 10-m wind velocity in CRuv, CRuv means the control region $(C R)$ where has high correlation coefficient $(C C)$ between the daily rainfall of Alishan meteorological station and 10-m wind velocity of NCEP CFSR on each grid node. $b$ : prw is the average precipitable water in CRprw, CRprw means the control region $(C R)$ where has high CC between the daily rainfall of Alishan meteorological station and precipitable water of NCEP CFSR on each grid node. 


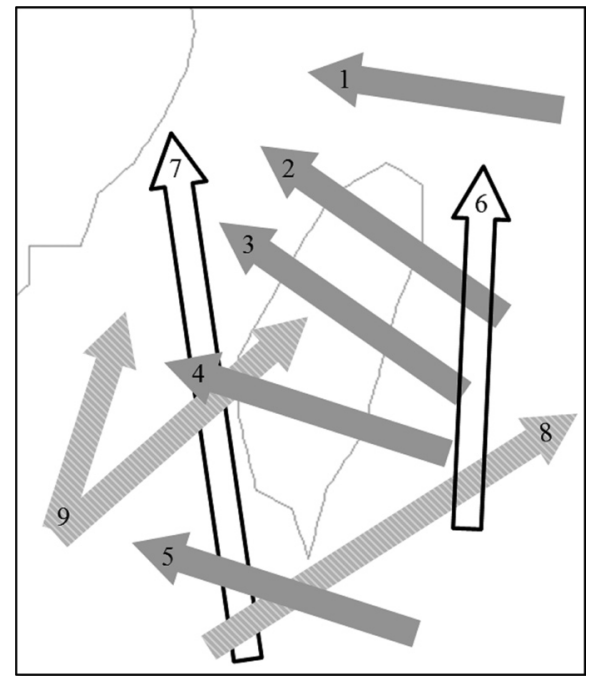

Fig. 3. Nine typhoon routes defined by Central Weather Bureau of Taiwan.

Table 2. Information on 20 typhoon events at Alishan meteorological station.

\begin{tabular}{c|ccccc}
\hline Route & Typhoon & Year & Date & Total Rainfall $(\mathbf{m m})$ & Daily Average Rainfall $\left(\mathbf{m m}\right.$ day $\left.^{-1}\right)$ \\
\hline \multirow{4}{*}{1} & Nelson & 1985 & $8 / 23-8 / 24$ & 751.3 & 375.7 \\
& Arer & 2004 & $8 / 24-8 / 25$ & 747.5 & 373.8 \\
& Matsa & 2005 & $8 / 04-8 / 06$ & 666.0 & 222.0 \\
\hline \multirow{6}{*}{2} & Norris & 1980 & $8 / 27-8 / 28$ & 595.7 & 297.9 \\
& Yancy & 1990 & $8 / 19-8 / 21$ & 1187.0 & 395.7 \\
& Herb & 1996 & $7 / 31-8 / 01$ & 986.5 & 493.3 \\
& Bilis & 2006 & $7 / 13-7 / 15$ & 789.0 & 263.0 \\
& Kalmaegi & 2008 & $7 / 17-7 / 19$ & 701.0 & 233.7 \\
\hline \multirow{6}{*}{3} & Polly & 1992 & $8 / 30-8 / 31$ & 729.3 & 364.7 \\
& Otto & 1998 & $8 / 04-8 / 05$ & 414.5 & 207.3 \\
& Haitang & 2005 & $7 / 18-7 / 20$ & 1226.0 & 408.7 \\
& Sepat & 2007 & $8 / 18-8 / 20$ & 793.0 & 264.3 \\
& Fung-Wong & 2008 & $7 / 28-7 / 29$ & 640.0 & 320.0 \\
& Morakot & 2009 & $8 / 08-8 / 10$ & 2965.0 & 741.3 \\
\hline \multirow{6}{*}{6} & Judy & 1979 & $8 / 24-8 / 26$ & 741.8 & 247.3 \\
& June & 1981 & $6 / 20-6 / 21$ & 306.3 & 343.2 \\
& Alex & 1987 & $7 / 27-7 / 28$ & 697.8 & 348.9 \\
& Ofelia & 1990 & $6 / 23-6 / 24$ & 474.5 & 237.3 \\
& Doug & 1994 & $8 / 08-8 / 10$ & 1048.5 & 349.5 \\
& Mindulle & 2004 & $7 / 03-7 / 05$ & 1725.0 & \\
\hline
\end{tabular}

More details about the STM can be found in the literature of WMO (2009).

The AI approach introduces an amplification index of southwesterly air flow precipitation (AISFP) as a multiplication factor into the STM. It is assumed that the SFP in a typhoon event has the potential to reach its maximum value. Therefore, this study defined the AISFP, which is the ratio of probable maximum SFP to SFP, for amplifying the PMP not considering the combined effect of typhoon and southwesterly air flow. Details for the AISFP calculation procedure can be found in section 3.2. For estimating the PMP, which considers the combined effect of typhoon and southwesterly air flow using the AI approach (called PMPST hereafter), the AISFP can be added into Eq. (1). 
After adding the AISFP into Eq. (1), the PMPTS estimation equation is as follows:

$$
\mathrm{PMPTS}_{n}=A I S F P \times P M P_{n}=\operatorname{AISFP} \times\left(M M F \times P_{n}\right)
$$

where $P M P T S_{n}$ means the PMP estimation by considering the combined effect of typhoon and southwesterly air flow for $n$-hr duration, which envelops the PMPTS estimations for all selected typhoon events.

The IS approach is also proposed in this work. The assumption of IS approach is that the typhoon and southwesterly air flow are two independent systems. Based on this assumption the typhoon events used in the IS approach have no interaction with the southwesterly air flow. These events are called "pure" typhoon events hereafter. The PMP considering the combined effect of typhoon and southwesterly air flow using the IS approach (called PMPTS* hereafter) is estimated by summing the PMP for pure typhoon and probable maximum SFP as follows.

$$
\operatorname{PMPTS}_{n}^{*}=P M P_{n}^{*}+P_{H M S} \times \frac{t}{24},\left\{\begin{array}{l}
t=n, n \leq 48 \\
t=48, n>48
\end{array}\right.
$$

where $\operatorname{PMPTS}_{n}^{*}$ means the PMP estimation for $n$-hr duration which envelops the PMPTS* estimations for all selected typhoon events. $P M P_{n}^{*}$ is the PMP estimation for $n$-hr duration on a pure typhoon event using the STM; $P_{H M S}$ denotes the daily probable maximum SFP estimated by the regression equation described in section $3.2 ; t / 24$ is used to adjust the daily (24-hr) $P_{H M S}$ for $n$-hr PMPTS $S_{n}^{*}$ estimation and a maximum value for $t$ is set to be 48 due to the 2-day (48-hr) persistence of a SFP event which is observed using the collected data set and described in the former section.

Since the proposed AI and IS approaches are based on the STM, the following section first describes the selection of representative persisting surface dew point and stations for PMP estimation in the STM. Both selection results are shown. The calculation procedure for the proposed AI and IS approaches are then introduced.

\subsection{Selection of Representative Persisting Surface Dew Point and Station}

For estimating PMP by the STM, MMF in Eq. (1) has to be determined. Based on the WMO's suggestion (WMO 2009), the representative persisting surface dew point (e.g., representative persisting 12-hr surface dew point) and the representative station have to be determined before the MMF calculation.

Precipitable water is a critical term for determining the MMF in Eq. (1), which can be calculated based on the representative persisting surface dew point. Under the pseudoadiabatic (i.e., liquid water in the air parcel is assumed to be removed as soon as the air parcel is condensed) assumption, the corresponding value between precipitable water and surface dew point is tabulated in Tables A.1.1 and A.1.2 of the WMO's Manual (WMO 2009). The representative persisting 12- and 24-hr surface dew points are commonly used for PMP estimation by the STM (Wiesner 1970). The WMO (2009) suggested the representative persisting 24-hr surface dew point in some tropical regions in which the storm durations are longer. Since Taiwan is partly located in the tropical region and the storm duration is always longer than $72 \mathrm{hr}$, the representative persisting 24 -hr surface dew point is used in this study.

The representative station plays an important role in providing the dew point data for the PMP estimation by the STM. The WMO (2009) remarked (1) the dew point records at the representative station appreciably shorter than approximately 50 years are unlikely to yield maximum values representative of the maximum atmospheric moisture, and (2) the advantage position of the representative station should be located between the rain area and moisture source. According to the above WMO's suggestions, the Tainan meteorological station in Fig. 1 is selected for providing the dew point data in this work.

\subsection{Calculation Procedures of AI and IS Approaches}

Both the AI and IS approaches have three main steps for PMP estimation considering the combined effect of typhoon and southwesterly air flow. The first two steps (i.e., Step 1: Select control regions (CRs), and Step 2: Establish linear regression equations for SFP estimation and calculate the probable maximum SFP) are the same for both the AI and IS approaches. Step 3 for the AI method is to calculate the AISFP for each typhoon event and PMPTS estimates. Step 3 for the IS method is to calculate the PMPTS* estimates by summing up the PMP for a pure typhoon and the probable maximum SFP. The flow chart for the AI and IS approaches is shown in Fig. 4.

\section{Step 1: Select CRs}

The CR is defined as a region where the rainfall at Alishan meteorological station has a significant relationship with each of the atmospheric variables (10-m wind velocity and precipitable water data). The daily rainfalls of Alishan meteorological station, 10-m wind velocity and precipitable water data of NCEP CFSR are used for the CR selection. The data period and format are described in the section of Study Area and Data Sets. The correlation coefficient (CC) between the daily rainfall and each of the atmospheric variables on each grid node is calculated. The significant region with high $\mathrm{CC}$ is delineated as the CR. After the CR of wind velocity $\left(\mathrm{CR}_{\mathrm{uv}}\right)$ and the $\mathrm{CR}$ of precipitable water $\left(\mathrm{CR}_{\mathrm{prw}}\right)$ are decided, the average wind velocity in $\mathrm{CR}_{\mathrm{uv}}$ and average precipitable water in $\mathrm{CR}_{\text {prw }}$ have to be calculated. The average wind velocity in $\mathrm{CR}_{\mathrm{uv}}$ means the average value of wind 
velocity for all grid nodes in $\mathrm{CR}_{\mathrm{uv}}$, which is abbreviated as "uv"; the average precipitable water in $\mathrm{CR}_{\text {prw }}$ means the average value of precipitable water for all grid nodes in $\mathrm{CR}_{\mathrm{prw}}$, which is abbreviated as "prw".

Step 2: Establish regression equations for SFP estimation and calculate the probable maximum SFP

Linear regression equations for the relationship between the rainfall at Alishan meteorological station and the two meteorological variables (uv and prw) are established using the leave-one-out cross-validation (LOOCV) method. The F-test is used to check the statistical significance of each regression equation. Two criteria, mean absolute percentage error (MAPE), and root mean square error (RMSE) are used to decide the optimal linear regression equation.

$M A P E=\frac{\sum_{i=1}^{n}\left|\frac{P_{r e g, i}-P_{o b s, i}}{P_{o b s, i}}\right|}{n} \times 100 \%$

$R M S E=\sqrt{\frac{\sum_{i=1}^{n}\left(P_{r e g, i}-P_{o b s, i}\right)^{2}}{n}}$

where $P_{\text {reg, } i}$ is the estimated rainfall of the $i^{\text {th }}$ SFP event using the regression equation $(\mathrm{mm}) ; P_{o b s, i}$ indicates the observed rainfall of the $i^{\text {th }}$ SFP event $(\mathrm{mm}) ; n$ denotes the total number of SFP events.

The probable maximum $\operatorname{SFP}\left(P_{\text {HMS }}\right)$ is calculated by the optimal regression equation, which can be obtained through substituting the $\mathrm{uv}_{\mathrm{sw} \text {,max }}$ and $\mathrm{prw}_{\mathrm{sw} \text {,max }}$ from the 14 SFP events to the optimal regression equation.

Step 3: Estimate PMPTS and PMPTS*, respectively, by AI and IS approaches

Calculating the AISFP for each typhoon event is calculated first in the AI approach. The definition of AISFP is:

$A I S F P_{i}=\frac{P_{H M S}}{P_{S T, i}}$

where $P_{H M S}$ is the probable maximum SFP, $P_{S T, i}$ denotes the SFP in the typhoon $i$, and $A I S F P_{i}$ is the ratio of $P_{H M S}$ to $P_{S T, i}$ for the typhoon $i$. AISFP $P_{\mathrm{i}}$ means the SFP in the typhoon $i$ has a growth room to reach the probable maximum SFP. $P_{S T, i}$ is calculated by substituting the uv and prw in the typhoon $i$ to the optimal regression equation under the following constraints:

$\begin{cases}\text { if } \mathrm{uv} \geq \mathrm{uv}_{\mathrm{sw}, \max } & \text { then } \mathrm{uv}=\mathrm{uv}_{\mathrm{sw}, \max } \quad \text { else } \mathrm{uv}=\mathrm{uv} \\ \text { if } \mathrm{prw} \geq \mathrm{prw}_{\mathrm{sw}, \max } \text { then prw }=\mathrm{prw}_{\mathrm{sw}, \max } \text { else prw }=\text { prw }\end{cases}$

After the AISFP for each typhoon event is calculated, the PMPTS for each typhoon event can be calculated using Eq. (2).

Two terms in Eq. (3) (i.e., $P M P^{*}$ and $P_{H M S}$ ) need to be calculated for PMPTS* estimation in the IS approach. The $P M P^{*}$ for each pure typhoon event is calculated using the

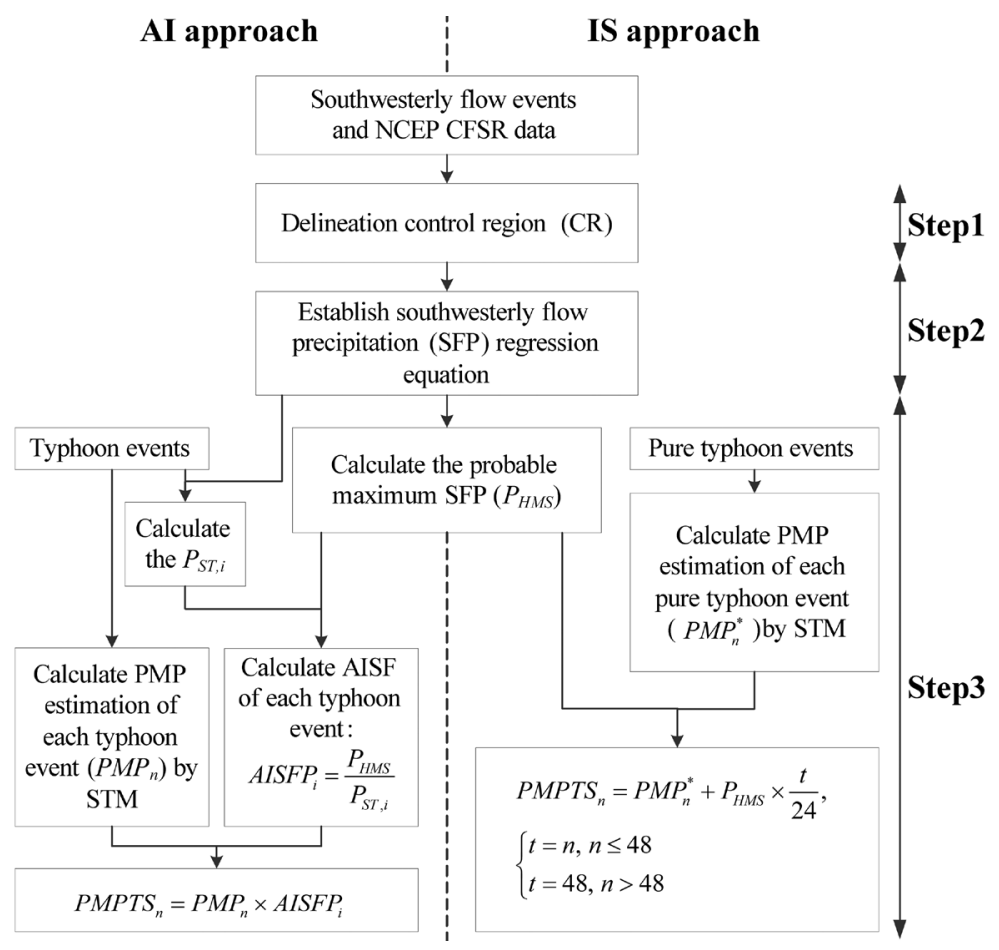

Fig. 4. Flow chart of AI and IS approaches. 
STM. The $P_{H M S}$ is calculated in Step 2. The PMPTS* estimation for each typhoon can then be estimated by substituting the $P M P^{*}$ for a pure typhoon event and $P_{H M S}$ into Eq. (3).

\section{RESULTS AND DISCUSSIONS}

This study proposes two approaches (i.e., the AI and IS approaches) to estimate PMPTS and PMPTS* in the study area, respectively. The results of AI and IS approaches are described in the following sections.

\subsection{Delineation of $\mathrm{CR}$}

Delineation of CR is Step 1 for the AI and IS approaches. For delineating the $\mathrm{CR}$, the $\mathrm{CC}$ between the daily rainfall at Alishan meteorological station and each of the two variables (i.e., wind velocity and precipitable water) for each grid are calculated. Figure 5a shows the $\mathrm{CC}$ between the daily rainfall at Alishan meteorological station and wind velocity for each grid. The $\mathrm{CR}$ of wind velocity is delineated by a black square where the $\mathrm{CC}$ for each grid is greater than $0.25(p<0.01)$. Figure $5 \mathrm{~b}$ shows the $\mathrm{CC}$ between the daily rainfall at Alishan meteorological station and precipitable water of each grid. The CR of precipitable water is delineated by a black square where the $\mathrm{CC}$ for each grid is greater than $0.25(p<0.01)$. The delineation of the above two CRs is reasonable since the rainfall at Alishan meteorological station results from precipitable water brought from southwest by southwesterly wind during the southwest monsoon season.

After determining the two $\mathrm{CRs}$ (i.e., $\mathrm{CR}_{\mathrm{uv}}$ and $\mathrm{CR}_{\mathrm{prw}}$ ), the mean wind velocity and precipitable water values in the CRs for the 14 southwesterly air flow events were calculated for establishing the SFP regression equation. Table 1 lists the daily precipitation $(\mathrm{P})$, the mean wind velocity value (uv) in the $\mathrm{CR}$, and the mean precipitable water value (prw) in the $\mathrm{CR}$, to establish the SFP regression equation.

\subsection{Regression Equation for SFP Estimation}

Step 2 for the AI and IS approaches is to establish the regression equation for SFP estimation. Since both of Spearman's CCs between $\mathrm{P}$ and uv and between $\mathrm{P}$ and prw are larger than 0.4 and their $\mathrm{p}$-values $(<0.05)$ reach statistical significance, it is assumed that daily precipitation $(\mathrm{P})$ has liner relationship with uv and prw. Four kinds of liner regression equations as Eqs. (8) - (11) were constructed and compared.

$P=a \times u v+C$

$P=a \times p r w+C$

$P=a \times u v+b \times p r w+C$

$P=a \times u v \times p r w+C$

Using the LOOCV method, each SFP event was used in turn for validation and the other left events were used for calibration (i.e., construction of regression equation). F-test was performed for each regression equation. A significance level of $\alpha=0.05$ is adopted in this work. Table 3 shows the LOOCV results. In the table, $\mathrm{C} 1$ represents the regression equation established (calibrated) by the $2^{\text {rd }}, 4^{\text {th }}$, $\ldots, 14^{\text {th }}$ events and verified by the $1^{\text {st }}$ event, $\mathrm{C} 2$ represents the regression equation established (calibrated) by the $1^{\text {st }}$, $3^{\text {rd }}, 4^{\text {th }}, \ldots, 14^{\text {th }}$ events and verified by the $2^{\text {nd }}$ event, and so forth. The table shows that the regression equation forms for (a)

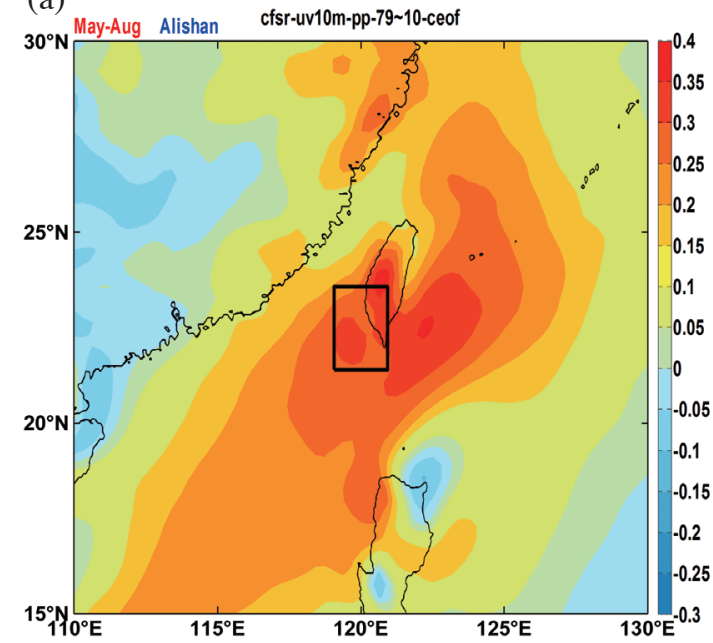

(b)

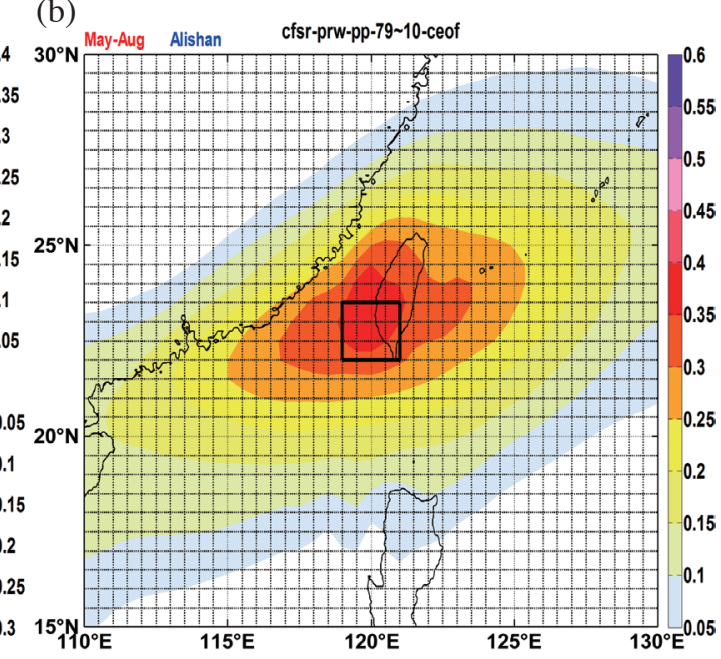

Fig. 5. Control regions (black square) for (a) 10-m wind velocity and (b) precipitable water. (Color online only) 
Table 3. F-statistics value for each regression equation.

\begin{tabular}{l|cccc}
\hline & Eq. (8) & Eq. (9) & Eq. (10) & Eq. (11) \\
\hline C1 & $8.96^{*}$ & 1.07 & $4.30^{*}$ & $9.54^{*}$ \\
C2 & $10.19^{*}$ & 1.50 & $4.88^{*}$ & $11.01^{*}$ \\
C3 & $10.00^{*}$ & 1.22 & $4.73^{*}$ & $10.43^{*}$ \\
C4 & $8.21 *$ & 0.63 & 3.77 & $8.42^{*}$ \\
C5 & $10.30^{*}$ & 1.54 & $4.69 *$ & $9.82^{*}$ \\
C6 & $7.90^{*}$ & 1.17 & 3.77 & $8.51^{*}$ \\
C7 & $8.80^{*}$ & 1.27 & $4.18^{*}$ & $9.42^{*}$ \\
C8 & $8.26 *$ & 1.81 & $4.00^{*}$ & $9.14^{*}$ \\
C9 & $13.10^{*}$ & 1.98 & $6.65^{*}$ & $15.09^{*}$ \\
C10 & $10.65^{*}$ & 1.35 & $5.02^{*}$ & $11.16^{*}$ \\
C11 & $8.96^{*}$ & 1.33 & $4.26^{*}$ & $9.61^{*}$ \\
C12 & $9.64 *$ & 1.57 & $4.69 *$ & $10.73^{*}$ \\
C13 & $8.62^{*}$ & 1.00 & $4.02^{*}$ & $8.91^{*}$ \\
C14 & $9.04 *$ & 2.85 & $4.76^{*}$ & $10.98^{*}$ \\
\hline
\end{tabular}

Note: $* p<0.05$.

Eqs. (9) and (10) are not suitable because all regression equations in the form of Eq. (9) and two regression equations (i.e., C2 and C14) in the form of Eq. (10) do not pass the Ftest $(p>0.05)$, respectively. The regression equations in the form of Eqs. (8) and (11) are suitable because all regression equations (i.e., $\mathrm{C} 1, \mathrm{C} 2, \ldots, \mathrm{C} 14)$ pass the F-test $(p<0.05)$. For each regression equation form for Eqs. (8) and (11), the mean coefficients for $a$ and $C$, respectively, for all regression equations (i.e., C1, C2, .., C14) were calculated as the representative coefficients. By comparing the values of MAPE and RMSE for the above two regression equation forms, the MAPE of Eqs. (8) and (11) are 23 and 21\%, respectively. The RMSE for Eqs. (8) and (11) are 80 and $78.8 \mathrm{~mm}$, respectively. The form for Eq. (11) with smaller values of MAPE and RMSE performs better than Eq. (8). Therefore, the regression equation developed using the form of Eq. (11) is the optimal equation for SFP estimation.

\subsection{PMPTS Estimation by AI Approach}

\subsubsection{AISFP Estimation}

AISFP estimation for each typhoon event is Step 3 of the AI approach. The maximum values of uv and prw (i.e., $\mathrm{uv}_{\max }$ and $\mathrm{prw}_{\max }$, respectively) in the CRs were obtained from the southwesterly air flow data set for $P_{H M S}$ estimation via Eq. (11). The values of $\mathrm{uv}_{\max }, \mathrm{prw}_{\max }$, and $P_{H M S}$ are $9.53 \mathrm{~m} \mathrm{~s}^{-1}, 66.54 \mathrm{~mm}$, and $375.8 \mathrm{~mm}^{-1 a y}$, respectively. The values of uv and prw in the CRs for each typhoon event were calculated for $P_{S T}$ estimation via Eq. (11). After obtaining the $P_{H M S}$ and the $P_{S T}$ for each typhoon event, the AISFP for each typhoon event can be estimated using the ratio of
$P_{H M S}$ to $P_{S T}$ in Eq. (6). Table 4 lists the uv, prw, $P_{S T}$, AISFP values for each typhoon event and the AISFP average for each typhoon route. An AISFP value larger in the table than 1 represents that the SFP in the typhoon event has the potential to reach the maximum value $\left(P_{H M S}\right)$. An AISFP value equal to 1 represents that the SFP value in the typhoon event has reached the maximum SFP. Moreover, the mean AISFPs for routes 1,2, and 6 (i.e., 1.2, 1.2, and 1.26, respectively) are larger than the mean AISFP for route 3 (i.e., 1.09).

The area of CR is approximately $200 \mathrm{~km} \times 150 \mathrm{~km}$, where the $\mathrm{uv}_{\max }$ and $\mathrm{prw}_{\max }$ are $9.53 \mathrm{~m} \mathrm{~s}^{-1}$ and 66.54 , respectively. In Taiwan, the influence region of a typhoon is defined using a circled area in which the wind velocity is over $15 \mathrm{~m} \mathrm{~s}^{-1}$. The radius of the circle area ranges from $100-350 \mathrm{~km}$, which is counted from the typhoon events during the past 50 years. When a typhoon's center passes Taiwan, the influence region of the typhoon is prone to cover the CR. The greater the proportion of the typhoon that covers the CR to the whole CR area, the AISFP is more likely to be one. The proportions of routes 1, 2, 3, and 6 are roughly estimated. In accordance with the proportions of routes $3,2,6$, and 1 in descending order, the number of typhoons on routes 3,2, 6, and 1 with AISFP equal to 1 are $5,3,2$, and 1 (Table 4), which means the AISFP estimation herein is reasonable.

\subsubsection{PMPTS Estimation}

Six typhoon events adopted for PMP estimation at Tsengwen Reservoir (WRA 2014) are used for PMPTS estimation in this work. After the AISFP is calculated, the PMPTS for each typhoon event can be calculated through Eq. (2). Table 5 shows the values of MMF and MMF multiplied by AISFP (MMF $\times$ AISFP) for the 6 typhoon events. The average AISFP (i.e., 1.2) for typhoon route 1 is used for Typhoon Gloria in 1963 since there is no NCEP CFSR data before 1979. The values of MMF $\times$ AISFP for Typhoon Gloria, Herb, Torji, Mindulle, Arer, and Morakot are 1.98, $1.29,2.80,1.09,1.34$, and 1.45 , respectively. The larger value of MMF $\times$ AISFP means the more extreme condition of the combined effect of typhoon and southwesterly air flow might occur. The PMPTS estimations using the AI approach for different durations $(6,12,18,24,36,48$, and $60 \mathrm{hr}$ ) are listed in Table 6. For comparison, the traditional PMP estimations using STM (WRA 2014) are also listed in the table.

Table 6 shows that the PMPST estimates using AI approach are larger than the traditional PMP estimates. The PMPTS estimates using the AI approach are larger than the traditional PMP estimates by $23,38,38,37,31,18$, and $12 \%$ of the traditional PMP estimates for the durations of 6,12 , $18,24,36,48$, and $60 \mathrm{hr}$, respectively. The mean percentage increase of the PMPTS estimates from the traditional PMP estimates for different durations is around $28 \%$. 
Table 4. Results of AISFP estimation.

\begin{tabular}{|c|c|c|c|c|c|c|}
\hline Route & Typhoon & uv $\left(\mathrm{m} \mathrm{s}^{-1}\right.$ day $\left.^{-1}\right)$ & prw (mm day $\left.{ }^{-1}\right)$ & $P_{\mathrm{ST}}\left(\mathrm{mm}\right.$ day $\left.^{-1}\right)$ & AISFP & Average of AISFP \\
\hline \multirow{3}{*}{1} & Nelson & 10.5 & 62.0 & 375.8 & 1.00 & \multirow{3}{*}{1.20} \\
\hline & Arer & 9.8 & 57.4 & 312.5 & 1.20 & \\
\hline & Matsa & 9.1 & 56.1 & 265.6 & 1.40 & \\
\hline \multirow{5}{*}{2} & Norris & 8.2 & 58.7 & 238.7 & 1.57 & \multirow{5}{*}{1.20} \\
\hline & Yancy & 12.4 & 69.9 & 375.8 & 1.00 & \\
\hline & Herb & 15.2 & 66.9 & 375.8 & 1.00 & \\
\hline & Bilis & 13.2 & 67.4 & 375.8 & 1.00 & \\
\hline & Kalmaegi & 8.1 & 62.3 & 256.3 & 1.47 & \\
\hline \multirow{6}{*}{3} & Polly & 11.4 & 69.3 & 375.8 & 1.00 & \multirow{6}{*}{1.09} \\
\hline & Otto & 8.2 & 59.4 & 242.3 & 1.55 & \\
\hline & Haitang & 14.4 & 66.0 & 375.8 & 1.00 & \\
\hline & Sepat & 11.4 & 65.2 & 375.8 & 1.00 & \\
\hline & Fung-Wong & 14.1 & 66.3 & 375.8 & 1.00 & \\
\hline & Morakot & 15.6 & 71.9 & 375.8 & 1.00 & \\
\hline \multirow{6}{*}{6} & Judy & 8.4 & 60.2 & 259.7 & 1.45 & \multirow{6}{*}{1.26} \\
\hline & June & 8.1 & 60.6 & 246.7 & 1.52 & \\
\hline & Alex & 8.3 & 61.5 & 260.9 & 1.44 & \\
\hline & Ofelia & 9.1 & 62.2 & 315.3 & 1.19 & \\
\hline & Doug & 10.4 & 61.7 & 375.8 & 1.00 & \\
\hline & Mindulle & 12.2 & 66.5 & 375.8 & 1.00 & \\
\hline
\end{tabular}

Table 5. Values for MMF, AISFP, and MMF $\times$ AISFP for each typhoon event.

\begin{tabular}{ccccccc}
\hline Typhoon (Year) & Gloria (1963) & Herb (1996) & Torji (2001) & Mindulle (2004) & Arer (2004) & Morakot (2009) \\
\hline MMF & 1.65 & 1.29 & 1.75 & 1.09 & 1.11 & 1.45 \\
AISFP & 1.20 & 1.00 & 1.60 & 1.00 & 1.21 & 1.00 \\
MMF $\times$ AISFP & 1.98 & 1.29 & 2.80 & 1.09 & 1.34 & 1.45 \\
\hline
\end{tabular}

Table 6. PMP estimates $(\mathrm{mm})$ by AI and IS approaches, and traditional STM for different durations, and the maximum observed rainfalls $(\mathrm{mm})$ of two typhoon events.

\begin{tabular}{c|c|ccccccc}
\hline \multicolumn{2}{c|}{} & \multicolumn{7}{c}{ Duration (hr) } \\
\cline { 3 - 9 } \multicolumn{2}{c|}{} & $\mathbf{6}$ & $\mathbf{1 2}$ & $\mathbf{1 8}$ & $\mathbf{2 4}$ & $\mathbf{3 6}$ & $\mathbf{4 8}$ & $\mathbf{6 0}$ \\
\hline PMPTS & AI approach & 1014 & 1560 & 1830 & 2218 & 2689 & 2816 & 2973 \\
\hline PMPTS $^{*}$ & IS approach & 728 & 1312 & 1807 & 2224 & 2804 & 3098 & 3227 \\
\hline PMP & Traditional STM & 596 & 977 & 1327 & 1621 & 2050 & 2380 & 2650 \\
\hline $\begin{array}{c}\text { Maximum observed } \\
\text { rainfall }\end{array}$ & Herb (1996) & $616^{+}$ & $1157^{+}$ & $1537^{+}$ & $1748^{+}$ & 1978 & 1986 & 1986 \\
\cline { 2 - 9 } & Morakot (2009) & 549 & 935 & 1273 & $1624^{+}$ & $2048^{\#}$ & $2361^{\#}$ & 2560 \\
\hline
\end{tabular}

Note: +: indicates that the maximum observed rainfall exceeds the PMP estimate by the traditional STM but does not exceed the PMP estimates by AI and IS approaches. \#: denotes that the maximum observed rainfall approaches to the PMP estimation by the traditional STM. 


\subsection{PMPTS* Estimation by IS Approach}

PMPTS* estimation for each typhoon event is Step 3 of the IS approach. The assumption of IS approach is that the two weather systems (i.e., pure typhoon and southwesterly air flow) are independent. Under this assumption, two pure typhoon events (i.e., Typhoon Gloria and Torji) in Table 5 are used for PMPTS* estimation using the IS approach. The procedure of IS approach to calculate the PMPTS* estimation is by summing up the PMP for a pure typhoon and $P_{\text {HMS }}$ in Eq. (3). $P_{H M S}$ estimation is calculated using the $\mathrm{uv}_{\max }$ and prw $_{\max }$ values in the CRs via Eq. (11). The PMPTS* estimations by the IS approach for different durations $(6,12,18$, 24, 36, 48, and $60 \mathrm{hr}$ ) are listed in Table 6.

Table 6 shows that the PMPTS* estimates using the IS approach are larger than the traditional PMP estimates. The PMPTS $^{*}$ estimates using the IS approach are larger than the traditional PMP estimates by 22, 34, 36, 37, 37, 30, and $22 \%$ of the traditional PMP estimates for the durations of 6,12 , $18,24,36,48$, and $60 \mathrm{hr}$, respectively. The mean percentage increase for the PMPTS* estimates from the traditional PMP estimates for different durations is around $31 \%$.

Finally, Table 6 also shows the maximum observed rainfalls caused by Typhoon Herb (1996) and Typhoon Morakot (2009), which have the combined effect with southwesterly air flow. The maximum observed 6-, 12-, 18-, and 24-hr rainfalls of Typhoon Herb exceed the PMP estimates by the traditional STM but do not exceed the estimates of PMPTS and PMPTS*. The maximum observed 24-hr rainfall of Typhoon Morakot exceeds the PMP estimate using the traditional STM but does not exceed the PMPTS and PMPTS*. Moreover, the maximum observed 36- and 48-hr rainfalls of Typhoon Morakot approach the PMP estimates using the traditional STM. Since the maximum observed rainfalls have exceeded the PMP estimates by the traditional STM but do not exceed the PMPTS and PMPTS* estimates, that gives the proposed approaches of this work extra confidence for providing reasonable results.

\section{CONCLUSIONS AND FUTURE WORK}

The important dynamic mechanism that caused Typhoon Morakot to bring heavy rainfall is the combined effect of typhoon and southwesterly air flow. This effect caused extreme damage in Taiwan. Therefore, the engineering community should reassess conventional PMP approaches and explore better ways to ensure more robust management of large infrastructure under the combined effect scenario, especially in Taiwan. This work proposes two tangible approaches (i.e., AI and IS approaches) based on the conventional PMP method (i.e., STM) to estimate the PMPTS which considers the combined effect of typhoon and southwesterly air flow. The AI approach assumes that the SFP in a typhoon event could reach its maximum value. The IS approach assumes that a typhoon and southwesterly air flow are independent weather systems. Based on these assumptions, the calculation procedures for the two approaches were constructed for a case study in the Tsengwen Reservoir catchment located in an area affected by the southwesterly air flow. For the AI and IS approaches, the mean percentage increases of PMPTS estimates and PMPTS* estimates from the traditional PMP estimates for different durations are around 28 and $31 \%$, respectively.

Although the two approaches proposed herein do not consider the dynamic mechanism of combined weather effect, we provide a pioneering way for PMPTS estimation based on a conventional PMP method. The assumptions of the two proposed approaches seem to simplify the mechanism of combined weather effect. Nevertheless, their results for PMPTS estimation are more conservative for infrastructure safety and the calculation processes are more easily understood for practical applications, which is very important to engineering community. In order to realize and solidify this work, future work may adopt the numerical weather model (e.g., the Weather Research \& Forecasting Model) for PMPTS estimation compared with PMPTS estimated by the AI and IS approaches. The nonlinear simulation methods (e.g., artificial neural network and support vector machine) may be used to establish the regression equation for SFP estimation improvement. For more comprehensive application the integrated method for PMP estimation covering all foreseeable storm scenarios can be developed in the future. Moreover, the climate change impact on PMP estimation is also an important issue (Kunkel et al. 2013; Rousseau et al. 2014; Stratz and Hossain 2014) and may be investigated in future work.

Acknowledgements This research was supported by Taiwan's (1) National Science Council (now: Ministry of Science and Technology) through NSC 100-2218-M-006-240 and (2) Water Resources Planning Institute, Water Resources Agency through 102052, 104013, and 105006 to National Cheng Kung University.

\section{REFERENCES}

Abbs, D. J., 1999: A numerical modeling study to investigate the assumptions used in the calculation of probable maximum precipitation. Water Resour. Res., 35, 785-796, doi: 10.1029/1998WR900013. [Link]

Bao, X. and F. Zhang, 2013: Evaluation of NCEP-CFSR, NCEP-NCAR, ERA-Interim, and ERA-40 reanalysis datasets against independent sounding observations over the Tibetan Plateau. J. Climate, 26, 206-214, doi: 10.1175/JCLI-D-12-00056.1. [Link]

Casas, M. C., R. Rodríguez, M. Prohom, A. Gázquez, and A. Redaño, 2011: Estimation of the probable maximum precipitation in Barcelona (Spain). Int.J. Climatol., 31, 
1322-1327, doi: 10.1002/joc.2149. [Link]

Chawla, A., D. M. Spindler, and H. L. Tolman, 2013: Validation of a thirty year wave hindcast using the Climate Forecast System Reanalysis winds. Ocean Model., 70, 189-206, doi: 10.1016/j.ocemod.2012.07.005. [Link]

Chen, L. C. and A. A. Bradley, 2007: How does the record July 1996 Illinois rainstorm affect probable maximum precipitation estimates? J. Hydrol. Eng., 12, 327-335, doi: 10.1061/(ASCE)1084-0699(2007)12:3(327). [Link]

Cheung, K. K. W., L. R. Huang, and C. S. Lee, 2008: Characteristics of rainfall during tropical cyclone periods in Taiwan. Nat. Hazards Earth Syst. Sci., 8, 1463-1474, doi: 10.5194/nhess-8-1463-2008. [Link]

Chien, F. C., 2015: The role of southwesterly flow in MCS formation during a heavy rain event in Taiwan on 12 13 June 2005. Terr. Atmos. Ocean. Sci., 26, 411-429, doi: 10.3319/TAO.2015.03.11.01(A). [Link]

Chien, F. C. and H. C. Kuo, 2011: On the extreme rainfall of Typhoon Morakot (2009). J. Geophys. Res., 116, D05104, doi: 10.1029/2010JD015092. [Link]

Douglas, E. M. and A. P. Barros, 2003: Probable maximum precipitation estimation using multifractals: Application in the eastern United States. J. Hydrometeorol., 4, 1012-1024, doi: 10.1175/1525-7541(2003)004<1012: PMPEUM>2.0.CO;2. [Link]

Fan, S., 1992: Hydraulic risk of flood disaster reduction at dams. US Department of Energy Publications, Paper 51, U.S. Department of Energy, Washington, D.C.

Fang, X., Y. H. Kuo, and A. Wang, 2011: The impacts of Taiwan topography on the predictability of Typhoon Morakot's record-breaking rainfall: A high-resolution ensemble simulation. Weather Forecast., 26, 613-633, doi: 10.1175/WAF-D-10-05020.1. [Link]

Fernando, W. C. D. K. and S. S. Wickramasuriya, 2011: The hydro-meteorological estimation of probable maximum precipitation under varying scenarios in Sri Lanka. Int. J. Climatol., 31, 668-676, doi: 10.1002/ joc.2096. [Link]

Hossain, F., I. Jeyachandran, and R. Pielke Sr., 2010: Dam safety effects due to human alteration of extreme precipitation. Water Resour. Res., 46, W03301, doi: 10.1029/2009WR007704. [Link]

Hsieh, L. S., J. H. Jang, H. J. Lin, and P. S. Yu, 2010: Flood prevention strategy in Taiwan: Lessons learned from Typhoon Morakot. J. Disast. Res., 5, 325-329, doi: 10.20965/jdr.2010.p0325. [Link]

Ishida, K., M. L. Kavvas, S. Jang, Z. Q. Chen, N. Ohara, and M. L. Anderson, 2015: Physically based estimation of maximum precipitation over three watersheds in Northern California: Relative humidity maximization method. J. Hydrol.Eng., 20, doi: 10.1061/(ASCE) HE.1943-5584.0001175. [Link]

Kulkarni,B.D.,S.Nandargi, and S.S.Mulye, 2010:Zonal estimation of probable maximum precipitation rain depths over the Krishna basin in peninsular India. Hydrolog. Sci.J., 55, 93-103, doi: 10.1080/02626660903529015. [Link]

Kunkel, K. E., T. R. Karl, D. R. Easterling, K. Redmond, J. Young, X. Yin, and P. Hennon, 2013: Probable maximum precipitation and climate change. Geophys. Res. Lett., 40, 1402-1408, doi: 10.1002/grl.50334. [Link]

Lagos-Zúñiga, M. A. and X. Vargas M., 2014: PMP and PMF estimations in sparsely-gauged Andean basins and climate change projections. Hydrolog. Sci. J., 59, 20272042, doi: 10.1080/02626667.2013.877588. [Link]

Lee, C. S., C. C. Wu, T. C. C. Wang, and R. L. Elsberry, 2011: Advances in understanding the "Perfect Monsoon-influenced Typhoon": Summary from international conference on Typhoon Morakot (2009). Asia-Pac. J. Atmos. Sci., 47, 213-222, doi: 10.1007/ s13143-011-0010-2. [Link]

Li, H. C., L. S. Hsieh, L. C. Chen, L. Y. Lin, and W. S. Li, 2014: Disaster investigation and analysis of Typhoon Morakot. J. Chin. Inst. Eng., 37, 558-569, doi: 10.1080/02533839.2012.736771. [Link]

Lin, C. Y., H. M. Hsu, Y. F. Sheng, C. H. Kuo, and Y. A. Liou, 2011: Mesoscale processes for super heavy rainfall of Typhoon Morakot (2009) over Southern Taiwan. Atmos. Chem. Phys., 11, 345-361, doi: 10.5194/ acp-11-345-2011. [Link]

Micovic, Z., M. G. Schaefer, and G. H. Taylor, 2015: Uncertainty analysis for Probable Maximum Precipitation estimates. J. Hydrol., 521, 360-373, doi: 10.1016/j.jhydrol.2014.12.033. [Link]

Rakhecha, P. R. and M. R. Kennedy, 1985: A generalised technique for the estimation of Probable Maximum Precipitation in India. J. Hydrol., 78, 345-359, doi: 10.1016/0022-1694(85)90112-X. [Link]

Rakhecha, P. R. and V. P. Singh, 2009: Applied Hydrometeorology, Springer Netherlands, 350 pp, doi: 10.1007/978-1-4020-9844-4. [Link]

Rousseau, A. N., I. M. Klein, D. Freudiger, P. Gagnon, A. Frigon, and C. Ratté-Fortin, 2014: Development of a methodology to evaluate probable maximum precipitation (PMP) under changing climate conditions: Application to southern Quebec, Canada. J. Hydrol., 519, 30943109, doi: 10.1016/j.jhydrol.2014.10.053. [Link]

Saha, S., S. Moorthi, H. L. Pan, X. Wu, J. Wang, S. Nadiga, P. Tripp, R. Kistler, J. Woollen, D. Behringer, H. Liu, D. Stokes, R. Grumbine, G. Gayno, J. Wang, Y. T. Hou, H. Chuang, H. M. H. Juang, J. Sela, M. Iredell, R. Treadon, D. Kleist, P. Van Delst, D. Keyser, J. Derber, M. Ek, J. Meng, H. Wei, R. Yang, S. Lord, H. van den Dool, A. Kumar, W. Wang, C. Long, M. Chelliah, Y. Xue, B. Huang, J. K. Schemm, W. Ebisuzaki, R. Lin, P. Xie, M. Chen, S. Zhou, W. Higgins, C. Z. Zou, Q. Liu, Y. Chen, Y. Han, L. Cucurull, R. W. Reynolds, G. Rutledge, and M. Goldberg, 2010: The ncep cli- 
mate forecast system reanalysis. Bull. Amer. Meteorol. Soc., 91, 1015-1057, doi: 10.1175/2010BAMS3001.1. [Link]

Stratz, S. A. and F. Hossain, 2014: Probable maximum precipitation in a changing climate: Implications for dam design. J. Hydrol. Eng., 19, doi: 10.1061/(ASCE) HE.1943-5584.0001021. [Link]

Tan, E., 2010: Development of a methodology for probable maximum precipitation estimation over the American River watershed using the WRF model. Ph.D. Thesis, University of California, Davis, CA, 194 pp.

Tao, W. K., J. J. Shi, P. L. Lin, J. Chen, S. Lang, M. Y. Chang, M. J. Yang, C. C. Wu, C. Peters-Lidard, C. H. Sui, and B. J. D. Jou, 2011: High-resolution numerical simulation of the extreme rainfall associated with Typhoon Morakot. Part I: Comparing the impact of microphysics and PBL parameterizations with observations. Terr. Atmos. Ocean. Sci., 22, 673-696, doi: 10.3319/TAO.2011.08.26.01(TM). [Link]

Van Nguyen, H. and Y. L. Chen, 2011: High-Resolution initialization and simulations of Typhoon Morakot (2009). Mon. Weather Rev., 139, 1463-1491, doi: 10.1175/2011MWR3505.1. [Link]

Wang, W., P. Xie, S. H. Yoo, Y. Xue, A. Kumar, and X. Wu, 2011: An assessment of the surface climate in the NCEP climate forecast system reanalysis. Climate Dyn., 37, 1601-1620, doi: 10.1007/s00382-010-09357. [Link]

Water Resource Agency (WRA), 2014: The $4^{\text {th }}$ Tsengwen Reservoir Safety Report, WRA, Taiwan. (in Chinese)

Wiesner, C. J., 1970: Hydrometeorology, Chapman and Hall, London, 240 pp.

World Meteorological Organization (WMO), 1986: Manual for Estimation of Probable Maximum Precipitation, $2^{\text {nd }}$
Ed., WMO 332, Geneva.

World Meteorological Organization (WMO), 2009: Manual on Estimation of Probable Maximum Precipitatio, $3^{\text {rd }}$ Ed., WMO 1045, Geneva.

Wu, L., J. Liang, and C. C. Wu, 2011: Monsoonal influence on Typhoon Morakot (2009). Part I: Observational analysis. J. Atmos. Sci., 68, 2208-2221, doi: 10.1175/2011JAS3730.1. [Link]

Xue, Y., B. Huang, Z. Z. Hu, A. Kumar, C. Wen, D. Behringer, and S. Nadiga, 2011: An assessment of oceanic variability in the NCEP climate forecast system reanalysis. Climate Dyn., 37, 2511-2539, doi: 10.1007/ s00382-010-0954-4. [Link]

Yen, T. H., C. C. Wu, and G. Y. Lien, 2011: Rainfall simulations of Typhoon Morakot with controlled translation speed based on EnKF data assimilation. Terr. Atmos. Ocean. Sci., 22, 647-660, doi: 10.3319/ TAO.2011.07.05.01(TM). [Link]

Yigzaw, W., F. Hossain, and A. Kalyanapu, 2013: Impact of artificial reservoir size and land use/land cover patterns on probable maximum precipitation and flood: Case of Folsom Dam on the American River. J. Hydrol. Eng., 18, 1180-1190, doi: 10.1061/(ASCE)HE.19435584.0000722. [Link]

Yu, P. S., M. H. Hsu, J. H. Jang, J. C. Fu, C. J. Huang, and S. H. Yeh, 2014a: Flood warning by ensemble of multiple hydrological models: A case study for Typhoon Morakot. J. Chin. Inst. Eng., 37, 570-581, doi: 10.1080/02533839.2012.736722. [Link]

Yu, P. S., T. C. Yang, C. M. Kuo, and S. T. Chen, 2014b: Development of an integrated computational tool to assess climate change impacts on water supply-demand and flood inundation. J. Hydroinformatics, 16, 710730, doi: 10.2166/hydro.2013.018. [Link] 